\title{
Identification of storm surge vulnerable areas in the Philippines through the simulation of Typhoon Haiyan-induced storm surge levels over historical storm tracks
}

\author{
J. P. Lapidez ${ }^{1}$, J. Tablazon ${ }^{1}$, L. Dasallas ${ }^{1}$, L. A. Gonzalo ${ }^{1}$, K. M. Cabacaba ${ }^{1}$, M. M. A. Ramos $^{1}$, J. K. Suarez ${ }^{1}$, \\ J. Santiago ${ }^{1}$, A. M. F. Lagmay ${ }^{1,2}$, and V. Malano ${ }^{3}$ \\ ${ }^{1}$ Nationwide Operational Assessment of Hazards, Quezon City, Philippines \\ ${ }^{2}$ National Institute of Geological Sciences, University of the Philippines-Diliman, Quezon City, Philippines \\ ${ }^{3}$ Philippine Atmospheric, Geophysical and Astronomical Services Administration, Quezon City, Philippines
}

Correspondence to: J. P. Lapidez (phillip@noah.dost.gov.ph)

Received: 01 October 2014 - Published in Nat. Hazards Earth Syst. Sci. Discuss.: 02 February 2015

Revised: 11 May 2015 - Accepted: 10 June 2015 - Published: 02 July 2015

\begin{abstract}
Super Typhoon Haiyan entered the Philippine Area of Responsibility (PAR) on 7 November 2013, causing tremendous damage to infrastructure and loss of lives mainly due to the storm surge and strong winds. Storm surges up to a height of $7 \mathrm{~m}$ were reported in the hardest hit areas. The threat imposed by this kind of natural calamity compelled researchers of the Nationwide Operational Assessment of Hazards (Project NOAH) which is the flagship disaster mitigation program of the Department of Science and Technology (DOST) of the Philippine government to undertake a study to determine the vulnerability of all Philippine coastal communities to storm surges of the same magnitude as those generated by Haiyan. This study calculates the maximum probable storm surge height for every coastal locality by running simulations of Haiyan-type conditions but with tracks of tropical cyclones that entered PAR from 1948-2013. One product of this study is a list of the 30 most vulnerable coastal areas that can be used as a basis for choosing priority sites for further studies to implement appropriate site-specific solutions for flood risk management. Another product is the storm tide inundation maps that the local government units can use to develop a risk-sensitive land use plan for identifying appropriate areas to build residential buildings, evacuation sites, and other critical facilities and lifelines. The maps can also be used to develop a disaster response plan and evacuation scheme.
\end{abstract}

\section{Introduction}

The water level oscillations, over and above the predicted astronomical tides in coastal or inland bodies of water, generated by the wind forcings from an atmospheric weather system are called storm surges (Murty, 1999). The specific factors affecting the height of the generated surge are the following: the storm's central pressure, wind intensity, translational forward speed, storm radius, storm approach angle, coastline geometry, and the local bathymetry (National Oceanic and Atmospheric Administration, National Weather Service, National Hurricane Center, 2014). The resulting flood induced by storm surge is a major cause of casualties and damages to coastal regions. The destructive elements produced by these surges lead scientists from all over the world to conduct research into storm surge risk assessments (Wu et al., 2002; Brown et al., 2007; Hallegatte et al., 2011; Rygel et al., 2006). The Philippines, with its $36289 \mathrm{~km}$ of coastlines, is highly susceptible to the ill effects of weather hazards (Yumul Jr. et al., 2011), such as storm surges. The country is also included in the regions that are most vulnerable to coastal flooding due to sea-level rise (Nicholls et al., 1999). Its low lying islands, long stretches of coastal areas, concave and gently sloping coastlines contribute to the enhancement of storm surge impacts. The country's geographical location also increases its exposure to storm surge hazard - it lies in the south western part of the Northwest Pacific basin which is considered to be the most active ocean basin, gen- 


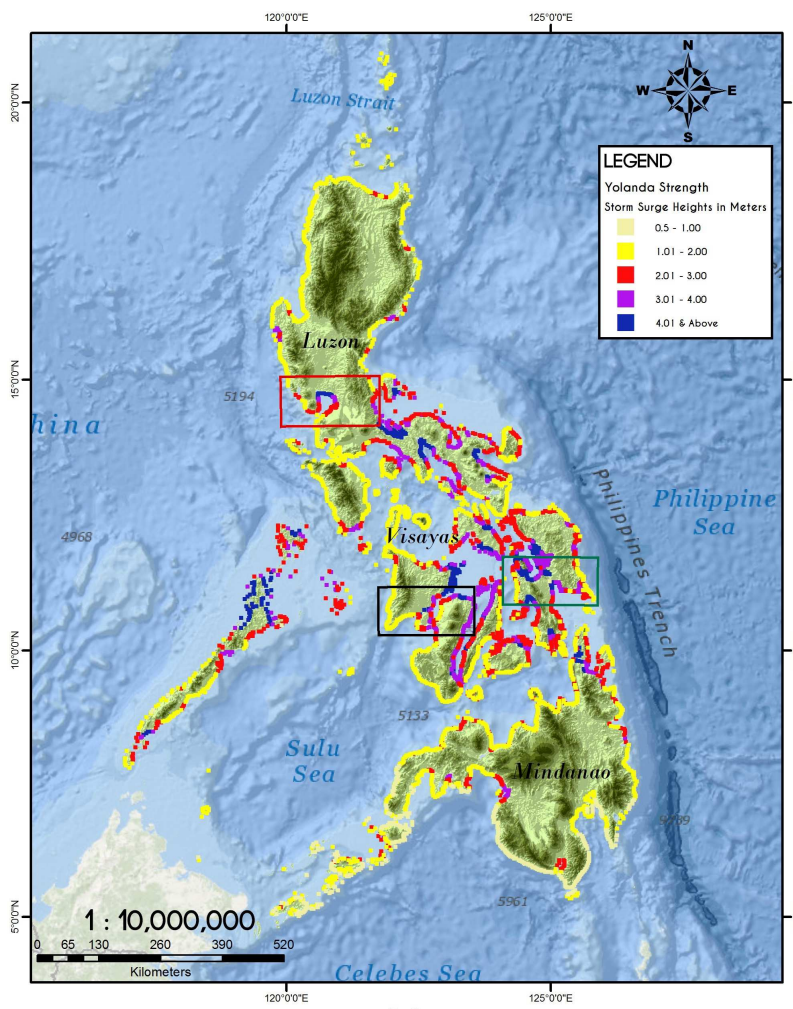

(a)

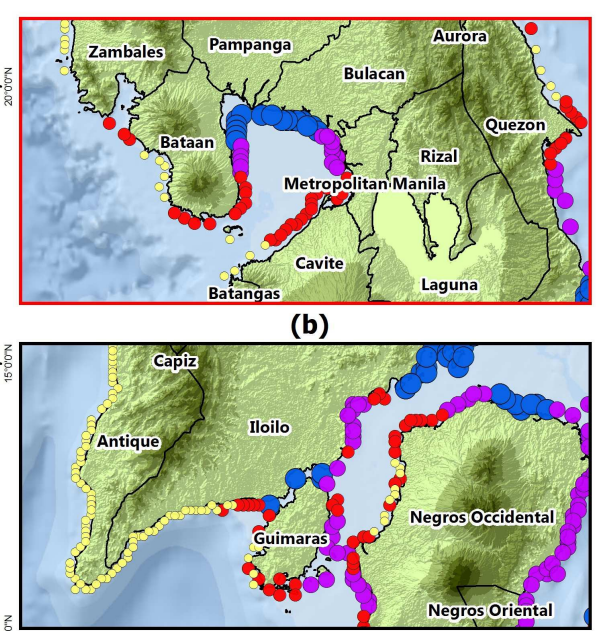

(c)

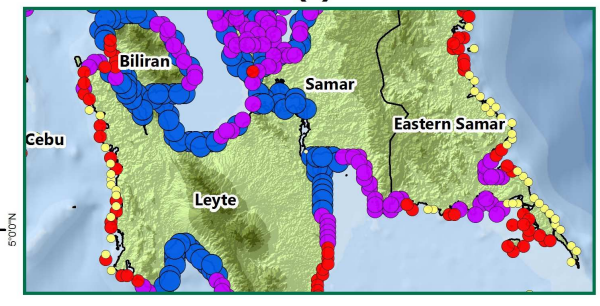

(d)

Figure 1. Maximum storm surge height (m) map for the (a) Philippines, (b) Metro Manila, (c) Iloilo, (d) Leyte.

erating an average of 26 tropical cyclones per year (National Oceanic and Atmospheric Administration, Atlantic Oceanographic and Meteorological Laboratory, 2000). An average of 20 typhoons enter the Philippine area of responsibility (PAR) annually, 9 of which make landfall passing through the southern part of Luzon island and eastern part of the Visayan islands. Refer to Fig. 1.

Typhoon Haiyan was the 25th typhoon that entered PAR in 2013. It started as a low pressure region in the West Pacific Ocean early on 2 November. Favorable environmental conditions prompted the atmospheric disturbance to undergo rapid intensification, upgrading the typhoon to category 5 on 7 November 2013 (National Oceanic and Atmospheric Administration, National Climatic Data Center, 2013). Haiyan, with an estimated 10 min maximum sustained winds of $235 \mathrm{~km} \mathrm{~h}^{-1}$ (Japan Meteorological Agency, 2014) is the strongest typhoon to make landfall in the country in recorded history. The intense wind, torrential rainfall and several-meter-high storm surge generated by the typhoon, resulted in widespread devastation in the central Philippines. This extreme event emphasized the necessity to forecast storm surge height and inundation in the Philippine coastal regions. The study's objective is to identify the areas in the Philippines that are most susceptible to extreme storm surges. The maximum probable storm surge height for every coastal locality is calculated by running multiple storm surge simula- tions using the intensity of Haiyan and tracks of tropical cyclones that entered PAR from 1948-2013. This provided an idea of the probable extent of damage if a Haiyan-intensity storm hit a certain area. Once the vulnerable coastal areas are identified, appropriate site-specific solutions to storm surge hazards can be studied to produce scientific evidence to guide management strategies. Outputs are also intended to enable the development of a risk-sensitive land use plan to identify appropriate areas for residential buildings, evacuation sites and other critical facilities. Inundation maps and hazard maps based on the worst case scenario for every area can also be used to develop a disaster response plan and evacuation scheme, to improve the regions resilience to typhoon driven storm surges.

\section{Methodology}

The Japan Meteorological Agency (JMA) keeps an archive of the best data of the typhoon track. These data are publicly available and can be downloaded from their website: http://www.jma.go.jp/jma/jma-eng/jma-center/ rsmc-hp-pub-eg/besttrack.html. A best track data text file contains information about all typhoons formed in the North western pacific basin for a specific year. The pertinent information in the best track data that are essential to the 
storm surge simulation are the following: the location of the typhoon center throughout its lifetime, the central pressure and maximum sustained wind speed values, and the radii to 50 and 30 knot winds. For this research, all the available best track data files which covers the years 1951 to 2013 were downloaded. For each typhoon, the information about the location of its center from the time of formation until the time of dissipation were extracted and were used as the basis of the tracks of the hypothetical typhoons used in the storm surge simulations.

The best track data of JMA from 1951 to 2013 was cross-referenced to the list of typhoons that entered PAR as recorded by the Philippine Atmospheric, Geophysical and Astronomical Services Administration (PAGASA). Only the typhoon tracks that crossed the PAR were used in the study.

Data about Typhoon Haiyan were taken from the 2013 best track data of the Japan Meteorological Agency - http://www.jma.go.jp/jma/jma-eng/jma-center/ rsmc-hp-pub-eg/Besttracks/bst2013.txt.

Hypothetical typhoons were created using the tracks of the selected typhoons and the central pressure, maximum sustained wind speed values, and radii to the 50 and $30 \mathrm{knot}$ winds of Haiyan. A total of 861 hypothetical typhoons were generated for this study.

Storm surge simulations for the 861 hypothetical typhoons were generated using the JMA Storm Surge Model. The model was developed by the JMA to simulate and predict the heights of storm surges generated by inland and offshore tropical cyclones. The model's numerical scheme is based on the two-dimensional shallow water equations consisting of vertically integrated momentum equations in two horizontal $x$ and $y$ directions:

$$
\begin{aligned}
& \frac{\partial \boldsymbol{U}}{\partial t}-f \boldsymbol{V}=-g(D+\eta) \frac{\partial\left(\eta-\eta_{0}\right)}{\partial x}+\frac{\tau_{\mathrm{s} x}}{\rho}-\frac{\tau_{\mathrm{b} x}}{\rho} \\
& \frac{\partial \boldsymbol{V}}{\partial t}+f \boldsymbol{U}=-g(D+\eta) \frac{\partial\left(\eta-\eta_{0}\right)}{\partial y}+\frac{\tau_{\mathrm{s} y}}{\rho}-\frac{\tau_{\mathrm{b} y}}{\rho}
\end{aligned}
$$

and the continuity equation:

$$
\frac{\partial \eta}{\partial t}+\frac{\partial \boldsymbol{U}}{\partial x}+\frac{\partial \boldsymbol{V}}{\partial y}=0
$$

$\boldsymbol{U}$ and $\boldsymbol{V}$ are mass fluxes in the $x$ and $y$ directions. Mathematically,

$$
\begin{gathered}
\boldsymbol{U}=\int_{-D}^{\eta} u \mathrm{~d} z \\
\boldsymbol{V}=\int_{-D}^{\eta} v \mathrm{~d} z .
\end{gathered}
$$

$f$ is the Coriolis parameter; $g$ is the gravitational acceleration; $D$ is water depth below mean sea level; $\eta$ is the surface elevation; $\eta_{0}$ is the water column height equivalent to the inverse barometer effect; $\rho$ is the density of water. $\tau_{\mathrm{s} x}$ and $\tau_{\mathrm{s} y}$ are the components of wind stress on the sea surface; and $\tau_{\mathrm{b} x}$ and $\tau_{\mathrm{b} y}$ are the stress components of bottom friction. Explicit finite difference method is used by the model to numerically integrate the equations.

The JMA Storm Surge Model calculates the wind and pressure fields using empirical distribution formula and gradient wind relation. It computes storm surges that are produced by the wind set up due to the strong onshore surface winds and the inverse barometer effect associated with the sudden decrease of pressure in the atmosphere (Hasegawa et al., 2012). The model assumes that sea levels and the static level of local surface pressures are balanced, with a difference in sea level generating inflow and outflow currents moving as a gravitational wave (Higaki et al., 2009). The inputs used to run the storm surge simulations are the typhoon best track data, domain bathymetry, and station files. The bathymetric data used in the simulations was the $2 \mathrm{~min}$ Global Gridded Elevation Data (ETOPO2) of the National Oceanic and Atmospheric Administration (NOAA). A station file contains a list of points inside the computational domain where the storm surge is computed. This file was used to specify the locations at which storm surge time series was calculated. A total of 4996 points corresponding to barangays along the entire coastline of the Philippines were listed in the station file used in this study. The JMA storm surge model simulation produces storm surge maps and time series files and plots. The time series output has a $10 \mathrm{~min}$ frequency. Storm surge maps show the storm surge height distribution inside the computational domain for each time step of the simulation.

For each of the 4996 station points, the maximum storm surge height developed by simulating all of the 861 typhoons was ranked and tabulated. This result, together with the population density of the area within $10 \mathrm{~m}$ low elevation coastal zones (Center for International Earth Science Information Network, 2007), was used to identify the priority sites for the development of inundation maps and hazard maps.

The simulated storm surge values were added to the maximum tide level obtained from WXTide, a software that contains a catalogue of worldwide astronomical tides, to come up with the worst-case storm tide levels. There are only 149 WXTide stations inside PAR. Tide values were computed for each of the 4996 surge points by performing distance-weighted averaging. Three tide stations were chosen to be used for interpolation for each surge point. The grouping was based on geographical proximity while maintaining that there should be no land mass obstruction between the points.

Maximum tide levels vary throughout the country, ranging from 1.2 to $1.5 \mathrm{~m}$.

The FLO-2D two-dimensional flood routing model was used to simulate the storm tide inundation in the selected priority sites, for the worst-case storm track. FLO-2D is a simple volume conservation model that uses the continuity equation and the dynamic wave momentum equation as its 


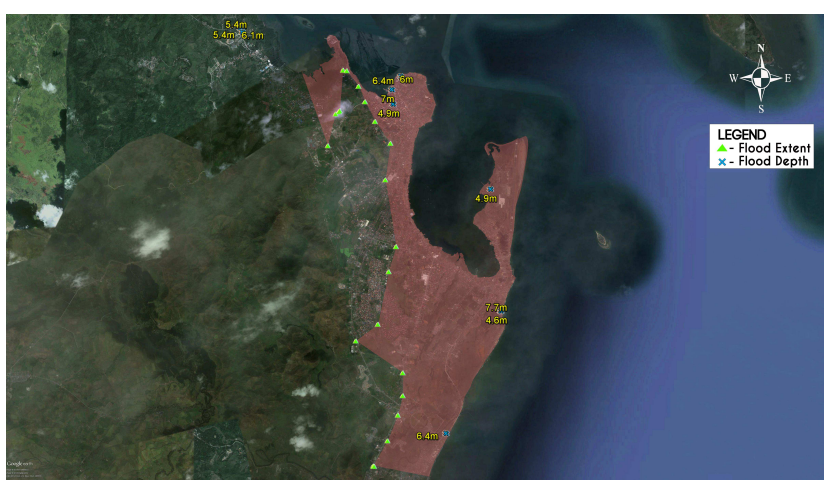

Figure 2. Results of the JSCE-PICE joint field survey.

governing equations. It can be used for a variety of flooding problems which includes overland progression of storm surges. It has been used for a similar application in the city of Waikiki, Oahu, Hawaii where the results showed the floodwave progression of ocean storm surges (O'Brien, 2005).

FLO-2D can be used to simulate coastal flooding by specifying water surface elevation as a function of time (stagetime relationship) for model grid elements along the coast. The model outputs are the predicted flow depths, velocities, discharge hydrographs, dynamic and static pressure, specific energy, and area of inundation.

The input parameters for inundation are the time series results from the JMA Storm Surge Model and the astronomical tide levels from WXTide, which are combined together to create the stage-time relationship. Airborne IfSARderived Digital Terrain Models (DTM) with a spatial resolution of $5 \mathrm{~m}$ was used to represent the topography of the study area. Appropriate Manning's $n$ roughness coefficient, based on land cover, was also assigned to the grid elements to represent the land friction value. Since inundation starts at the shoreline, the detailed shorelines of the cities were also traced using Google Earth aerial photos. These were identified in the grid system of the model and assigned the timestage storm tide data.

\section{Validation}

Representatives from the Japanese Society of Civil Engineers (JSCE) and Philippine Institute of Civil Engineers (PICE) conducted a joint survey on Tacloban, Leyte (Refer to Figs. 1d, 2, and 3) to gather data about the inundation depth and extent during the Haiyan flooding. The results of their survey were used to validate the simulations of this study. Their survey results are summarized in Fig. 2.

Comparing the survey results to the simulation results shows that there are areas where the simulation underestimated the flooding depth. This may be due to wave run-ups that the model cannot capture. There is also a discrepancy in the inundation extent which may be due to the value of
Table 1. Top 30 provinces and cities with a high storm surge level and LECZ population density.

\begin{tabular}{|c|c|c|c|c|c|}
\hline Rank & Province & $\begin{array}{c}\text { Max } \\
\text { surge } \\
\text { height } \\
(\mathrm{m})\end{array}$ & Latitude & Longitude & $\begin{array}{l}\text { Population } \\
\text { density } \\
\left(\text { per } \mathrm{km}^{2}\right)\end{array}$ \\
\hline 1 & Samar & 7.45 & 11.45 & 124.90 & $100-250$ \\
\hline 2 & Leyte & 6.84 & 11.37 & 124.77 & $>1000$ \\
\hline 3 & Palawan & 6.71 & 10.80 & 119.37 & $25-100$ \\
\hline 4 & Iloilo & 6.29 & 11.35 & 123.15 & $500-1000$ \\
\hline 5 & Biliran & 6.26 & 11.47 & 124.57 & $100-250$ \\
\hline 6 & Camarines Sur & 6.17 & 13.67 & 123.57 & $500-1000$ \\
\hline 7 & Quezon & 5.86 & 13.85 & 122.53 & $100-250$ \\
\hline 8 & Masbate & 5.45 & 12.27 & 123.77 & $100-250$ \\
\hline 9 & Southern Leyte & 5.32 & 10.28 & 125.05 & $100-250$ \\
\hline 10 & Bataan & 5.04 & 14.73 & 120.60 & $500-1000$ \\
\hline 11 & Dinagat Islands & 5.00 & 9.97 & 125.53 & $100-250$ \\
\hline 12 & Surigao del Norte & 5.00 & 9.90 & 125.48 & $100-250$ \\
\hline 13 & Cebu & 4.77 & 10.40 & 123.63 & $250-500$ \\
\hline 14 & Pampanga & 4.76 & 14.75 & 120.62 & $250-500$ \\
\hline 15 & Bohol & 4.45 & 10.17 & 124.33 & $250-500$ \\
\hline 16 & Bulacan & 4.42 & 14.72 & 120.85 & $100-250$ \\
\hline 17 & Negros Occidental & 4.41 & 10.97 & 123.33 & $250-500$ \\
\hline 18 & Guimaras & 4.41 & 10.75 & 122.70 & $100-250$ \\
\hline 19 & Albay & 4.36 & 13.20 & 123.85 & $250-500$ \\
\hline 20 & Negros Oriental & 4.05 & 9.57 & 123.17 & $100-250$ \\
\hline 21 & Capiz & 4.04 & 11.53 & 123.07 & $250-500$ \\
\hline 22 & Metro Manila & 3.90 & 14.62 & 120.93 & $>1000$ \\
\hline 23 & Eastern Samar & 3.87 & 11.20 & 125.60 & $100-250$ \\
\hline 24 & Surigao del Sur & 3.72 & 9.42 & 125.97 & $25-100$ \\
\hline 25 & Camarines Norte & 3.69 & 14.18 & 122.32 & $100-250$ \\
\hline 26 & Maguindanao & 3.65 & 7.38 & 124.22 & $500-1000$ \\
\hline 27 & Lanao del Sur & 3.65 & 7.3833 & 124.1667 & $<25$ \\
\hline 28 & Zamboanga del Sur & 3.59 & 7.65 & 123.10 & $25-100$ \\
\hline 29 & Sulu & 3.46 & 6.05 & 121.32 & $100-250$ \\
\hline 30 & Marinduque & 3.39 & 13.53 & 122.18 & $100-250$ \\
\hline
\end{tabular}

the roughness coefficient used in the inundation modeling. A land cover survey should also be conducted to correct the roughness coefficient used for modeling. Another possible source of error is the uncertainty in the model results because of the output frequency. The highest output frequency that can be produced by the model is a 10 min interval storm surge time series. However, sudden increases in surge height may occur within this interval. This uncertainty causes error in the representation of the peak in inundation. The discrepancies are summarized in Fig. 3.

\section{Results}

Table 1 lists the provinces with the highest 30 simulated storm surge heights together with its corresponding lowelevation coastal zone (LECZ) population density.

The maximum storm surge heights for all of the coastal regions of the Philippines are represented in Fig. 1a. Figure 1b$\mathrm{d}$ shows a closer view of the provinces of Metro Manila, Iloilo, and Leyte.

The city of Metro Manila and the provinces of Iloilo and Leyte were chosen for storm surge inundation modeling and storm surge hazard mapping. The three areas were chosen 

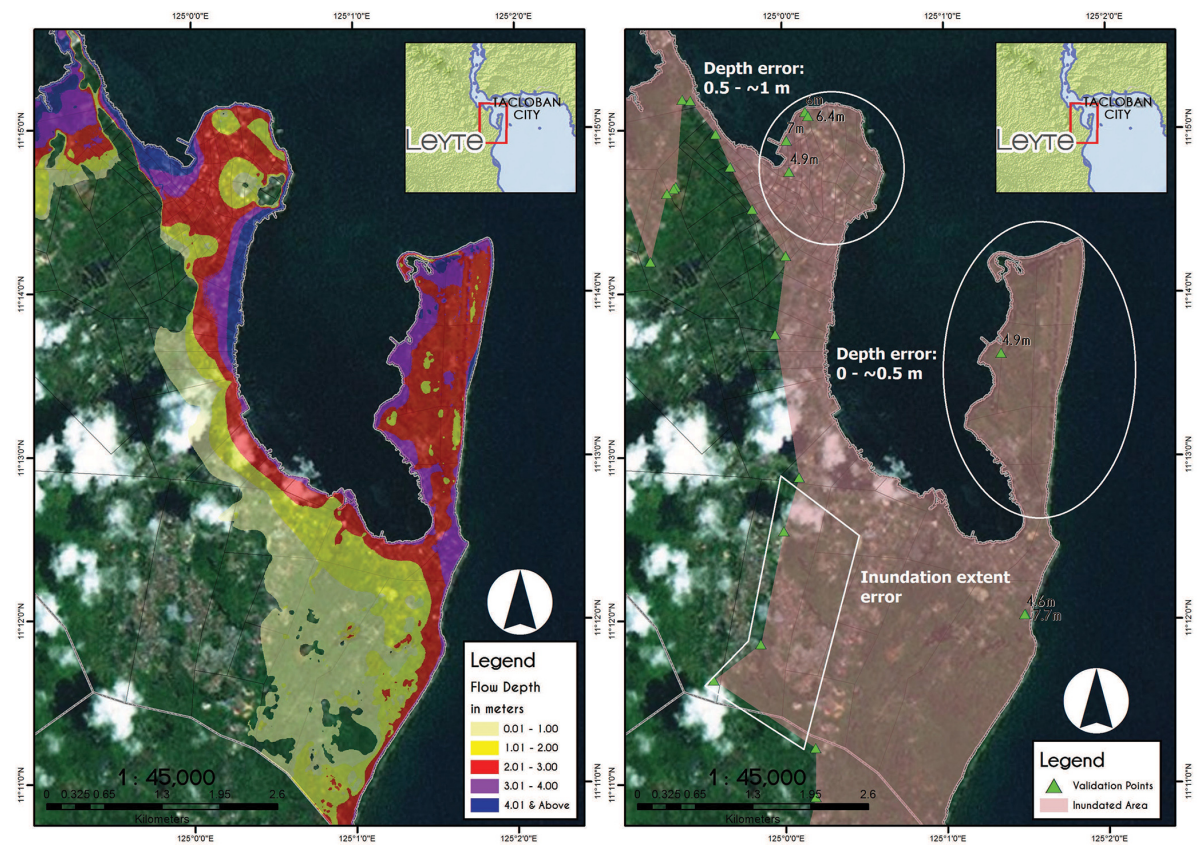

Figure 3. Error in height and extent of inundation (left panel: simulation result, right panel: survey result).

because of their potential to be impacted by high storm surge heights and their high LECZ population density as seen in Table 1.

The tracks of the typhoons that generated the maximum storm surge height in Metro Manila, Iloilo, and Leyte are shown in Fig. 4. Track of Typhoon Georgia (1964) generated the maximum storm surge height in Metro Manila. Tropical depression Rolly (2008) and Typhoon Haiyan (2013) generated the maximum storm surge height in Iloilo and Leyte respectively. The resulting inundation maps for Metro Manila, Iloilo, and Leyte, together with topographic elevation profiles at the marked transects are shown in Figs. 5-7 respectively.

\section{Discussion}

In Fig. 1, it is seen that the points that produce the highest surges concentrate in the central part of the country including the entire Visayas, some parts of southern Luzon, and some parts of northern Mindanao. This is because the majority of the typhoons that make landfall pass through this corridor. Further investigation in the provinces also shown in Fig. 1 reveals that the shape and characteristics of the coast contribute to the potential to generate high surges. Shallow bays, such as in the case of Samar, Leyte, Palawan, Biliran, Camarines sur, Quezon, and Manila, are highly vulnerable to occurrences of high surges. Barrier islands, on the other hand, can provide protection as seen in the northern part of Iloilo with the southern part being covered by the neighboring island Negros.

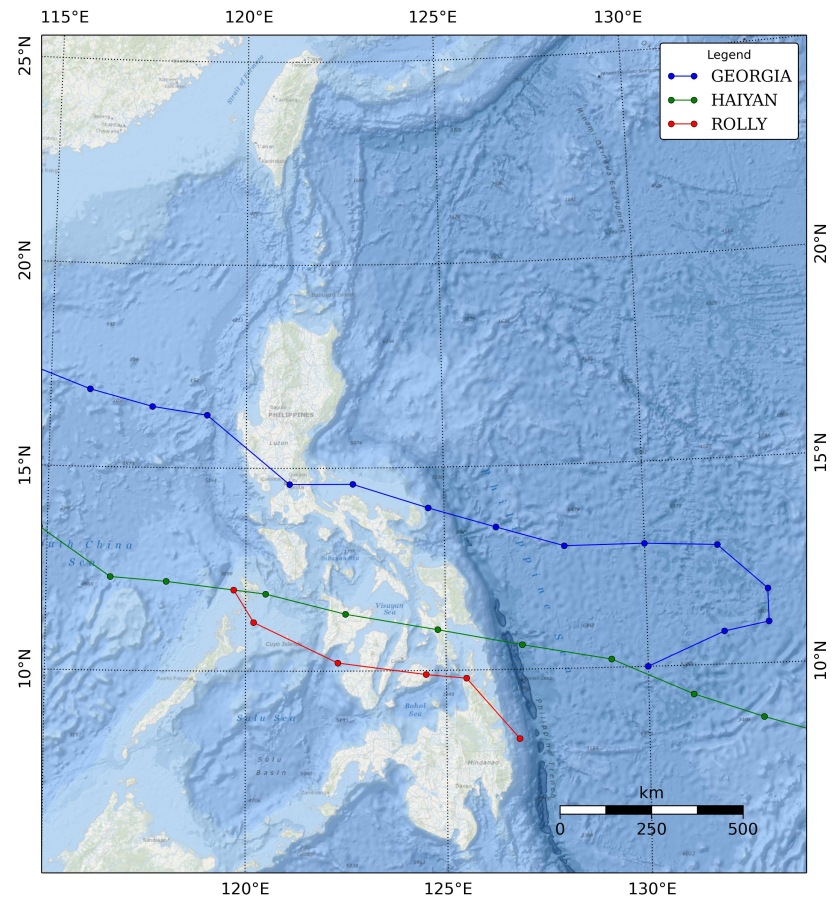

Figure 4. Tracks of Typhoon Georgia (1964), Tropical Depression Rolly (2008), and Typhoon Haiyan (2013).

In the inundation modeling, the flow of water is mainly controlled by the topography of the land over which the water flows. Thus, it is worthy to investigate the topographic factors that contribute to the depth and extent of the flooding. 

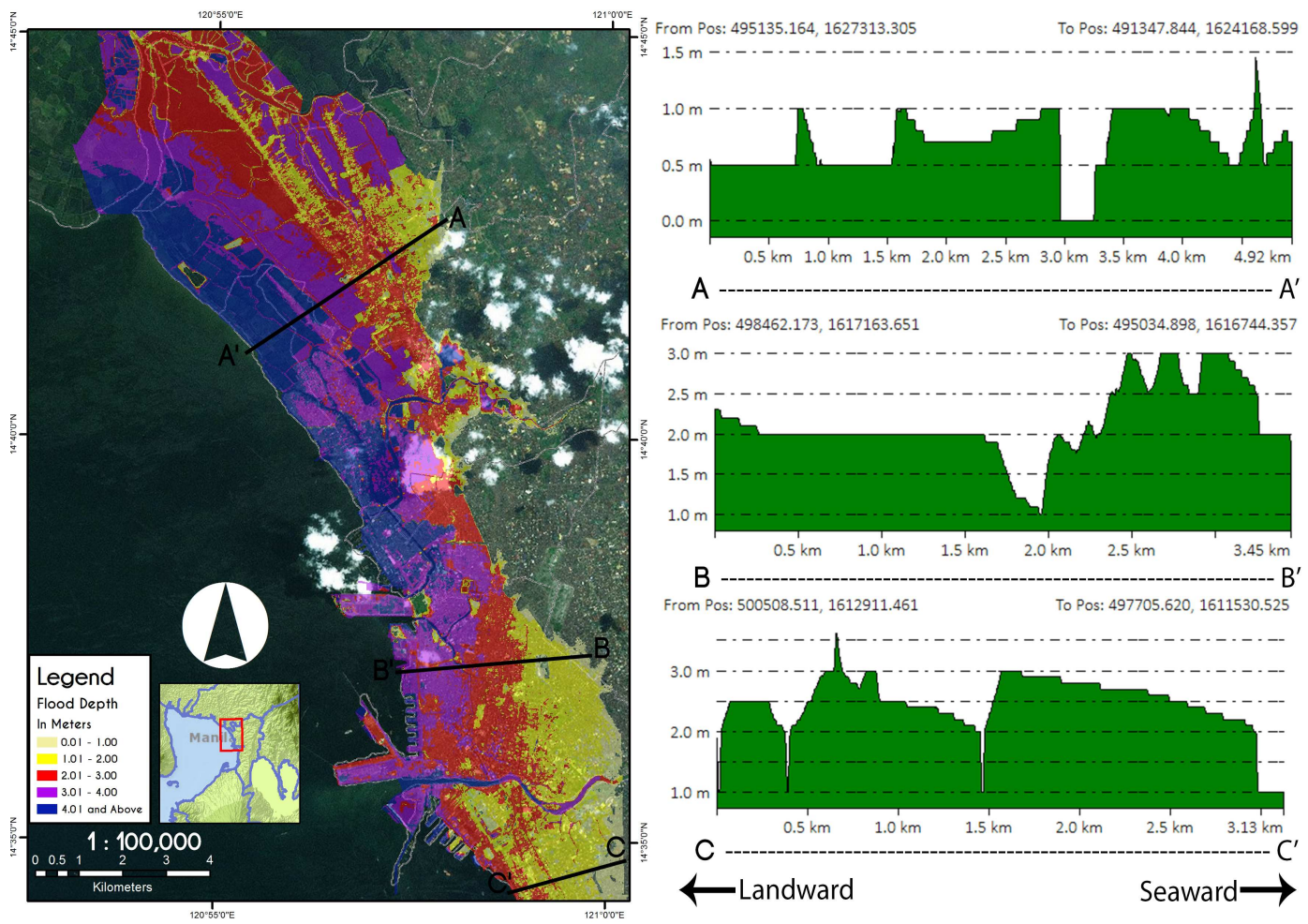

Figure 5. Manila inundation map with topographic elevation profiles at the marked transects (variable $y$ axis scale to clearly display the local variation in terrain).

Figures 6-8 show the flood maps with topographic elevation profiles along several transects.

In transect A-A' of Iloilo (Fig. 6), it is seen that the land elevation in the seaward direction is above $2.5 \mathrm{~m}$, higher than the inland elevation of about $1.0 \mathrm{~m}$. This explains why the flooding in this area is much lower compared with the areas around B-B' and C-C' of Iloilo. However, this may also lead to a longer retention time of flood waters as it can not easily drain back to the sea. The low elevation in the seaward direction of $\mathrm{B}^{-\mathrm{B}}$ ' is a reason for high flooding in the area. The land is also almost flat which contributes to the greater inland extent of inundation. $\mathrm{C}-\mathrm{C}^{\prime}$ has the worst condition. It has the lowest land elevation in the seaward direction, a flat landscape, and is situated near two rivers.

Transect A-A' of Manila (Fig. 5) has the lowest elevation among the three transects which is why the highest flooding occurs in this area. There is also a river directly crossing A-A' which further adds water to the flood extent when it overflows. There are large rivers in the north and south of B-B' adding water volume in the area. The elevation in the landward direction of $\mathrm{C}-\mathrm{C}^{\prime}$, about $2.5 \mathrm{~m}$, is higher than the elevation in the landward direction of B-B' of $2.0 \mathrm{~m}$. This forces the water to flow from the area near $\mathrm{C}-\mathrm{C}$ ' to $\mathrm{B}-\mathrm{B}$ '. Transects A-A', B-B', and C-C' show that the landscape in entire region has gentle slopes because of urbanization, allowing flood water to propagate farther inland.
Land masses that extend outward in the sea such as those in transects A-A' and C-C' of Leyte (Figs. 7 and 8) are vulnerable to flooding because they are surrounded by coastal waters and can become flooded from several directions at once. B-B' has a steep slope near the coast which effectively reduces the inundation extent in the area. D-D' has a relatively higher elevation but also has a flat landscape. This results in lower flood depths, but a greater inundation extent.

Referring to Fig. 8, it is seen that in transect $\mathrm{A}^{*}-\mathrm{A}^{*}$ ' there is a high elevation area towards the end of $\mathrm{A}^{*}$ so the flood water is more likely to come from the direction of $\mathrm{A}^{*}$. Transect $C^{*}-C^{*}$ ' shows that the topography in this area is relatively flat. This means that flood water can easily enter from both the eastern and western coasts of the peninsula. In the

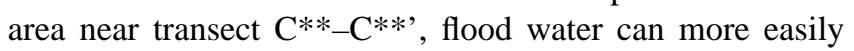
enter the peninsula from the $\mathrm{C}^{* *}$, direction because of the lower elevation and favorable slope in this direction.

\section{Conclusions}

In this study, a method is presented to assess coastal vulnerability across the Philippines. Storm surge simulations were done using 861 hypothetical typhoons with the intensity of typhoon Haiyan and tracks of historical typhoons that entered the PAR from year 1948 to 2013 . The highest simulated storm surge occurrence for every coastal area is collected and 


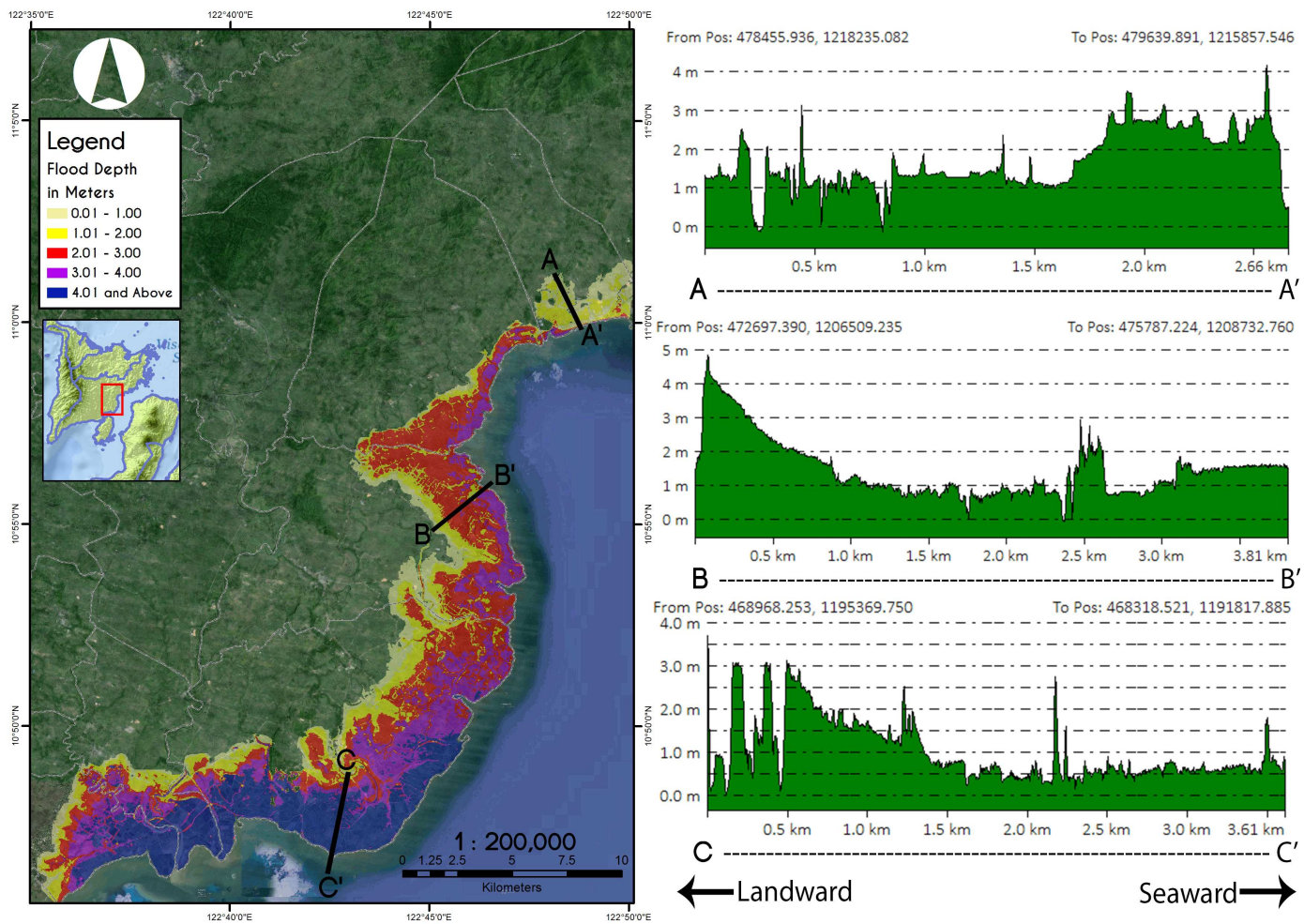

Figure 6. Iloilo inundation map with topographic elevation profiles at the marked transects (variable $y$ axis scale to clearly display the local variation in terrain).
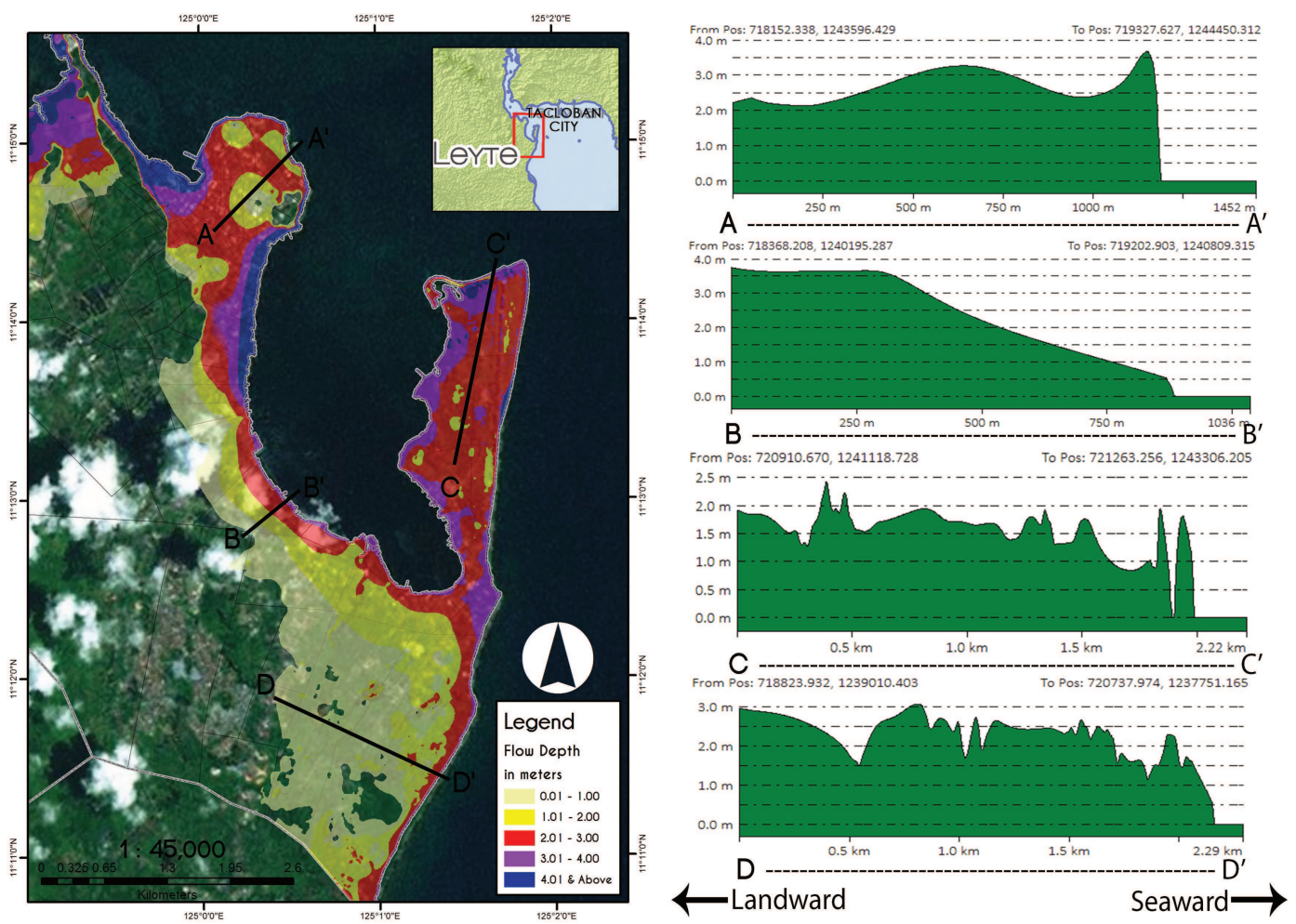

Figure 7. Leyte inundation map with topographic elevation profiles at the marked transects (variable $y$ axis scale to clearly display the local variation in terrain). 


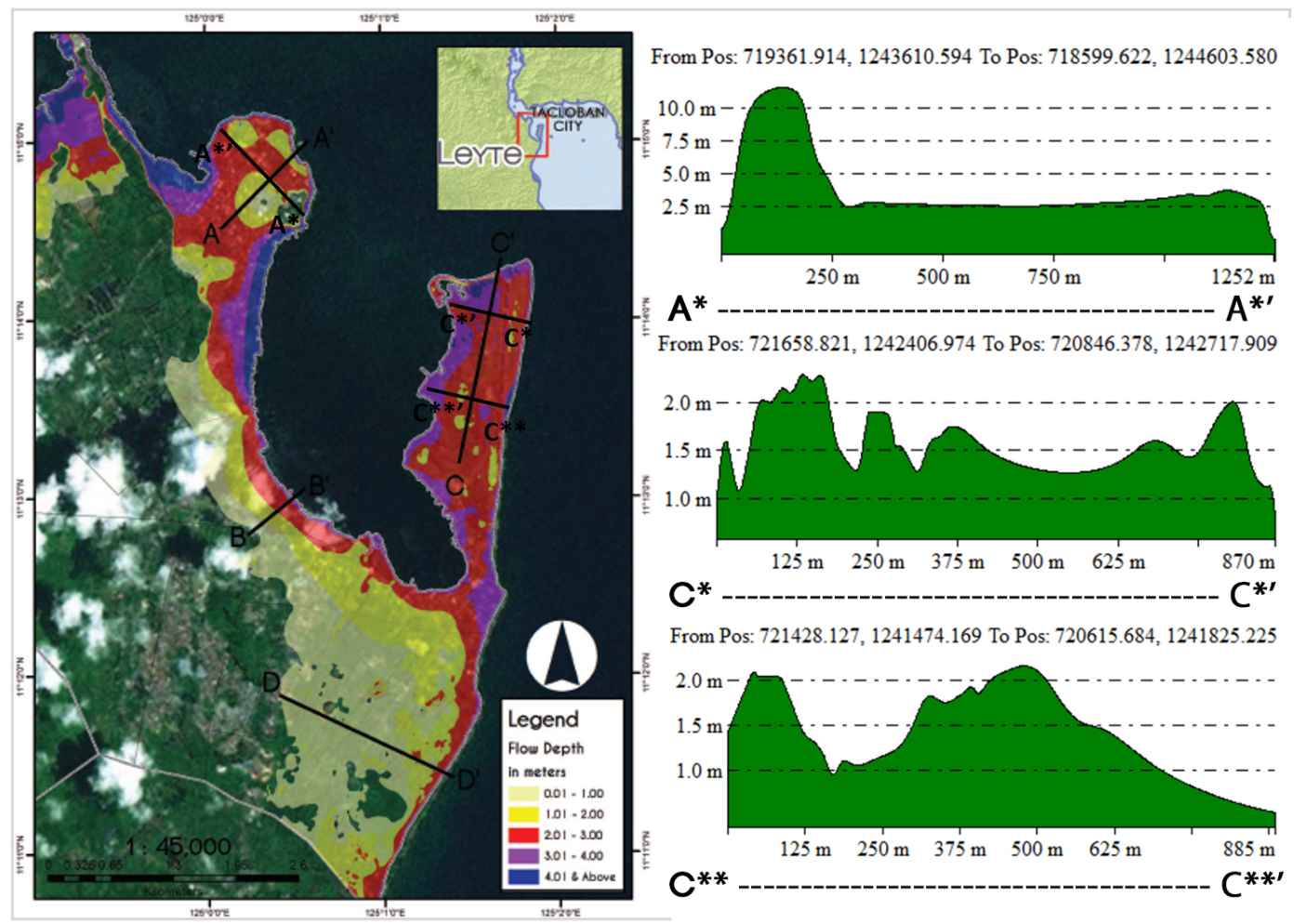

Figure 8. Leyte inundation map with topographic elevation profiles at the marked transects (variable $y$ axis scale to clearly display the local variation in terrain).

summarized to rank the vulnerability of each area relative to one another.

Coastal areas in the central Visayas (Samar, Leyte, Iloilo, Palawan, Cebu, Negros, Bohol), southern Luzon (Bicol, Quezon, Metro Manila, Bulacan), and north eastern Mindanao (Surigao) are the most vulnerable to high storm surges. This is because these regions have the characteristic of gently sloping coasts, shallow bays and are also frequently passed by typhoons. These areas should be subjected to detailed storm surge studies to implement appropriate site-specific solutions.

The resulting storm tide inundation maps and hazard maps can be used by the local government units to develop a Risk-Sensitive Land Use Plan for identifying appropriate areas to build residential buildings, evacuation sites, and other critical facilities and lifelines. The maps can also be used to develop a disaster response plan and evacuation scheme.

Edited by: P. Ciavola

Reviewed by: two anonymous referees

\section{References}

Brown, J. D., Spencer, T., and Moeller, I.: Modeling storm surge flooding of an urban area with particular reference to modeling uncertainties: a case study of Canvey Island, United Kingdom, Water Resour. Res., 43, W06402, doi:10.1029/2005WR004597, 2007.

Center for International Earth Science Information Network CIESIN-Columbia University: Population Density within and outside of a 10-meter low elevation coastal zones (LECZ) 2000, can be retrieved in: http://www.preventionweb.net/files/ 7700_ThePhilippines10mLECZandpopulationdensity1.pdf, previously accessed at: http://sedac.ciesin.columbia.edu (last access: September 2014) 2007.

Hallegatte, S., Ranger, N., Mestre, O., Dumas, P., Corfee-Morlot, J., Herweijer, C., and Wood, R. M.: Assessing climate change impacts, sea level rise and storm surge risk in port cities: a case study on Copenhagen, Climatic Change, 104, 113-137, 2011.

Hasegawa, H., Kohno, N., and Hayashibara, H.: JMA's Storm Surge Prediction for the WMO Storm Surge Watch Scheme (SSWS), Tech. rep., Office of Marine Prediction, Japan Meteorological Agency, RSMC Tokyo-Typhoon Center Technical Review, Tokyo, 2012.

Higaki, M., Hayashibara, H. H., and Nozaki, F.: Outline of the Storm Surge Prediction Model at the Japan Meteorological Agency, Tech. rep., Office of Marine Prediction, Japan Meteorological Agency, RSMC Tokyo-Typhoon Center Technical Review, Tokyo, 2009. 
Japan Meteorological Agency: Western North Pacific Typhoon Best Track File, available at: http://www.jma.go.jp/jma/jma-eng/ jma-center/rsmc-hp-pub-eg/besttrack.html, last access: January 2014.

Murty, T.: Storm surges in the marginal seas of the North Indian Ocean, in: WMO/UNESCO Sub-Forum on Science and Technology in Support of Natural Disaster Reduction, vol. WMON0 914, World Meteorological Organization, Geneva, 130-139, 1999.

National Oceanic and Atmospheric Administration, Atlantic Oceanographic and Meteorological Laboratory: Average, Standard Deviation and Percent of Global Total of the Number of Tropical Storms, Hurricane-Force Tropical Cyclones and Intense Hurricane-Force Tropical Cyclones, available at: http: //www.aoml.noaa.gov/hrd/Landsea/climvari/table.html (last access: May 2014), 2000.

National Oceanic and Atmospheric Administration, National Climatic Data Center: State of the Climate: Hurricanes and Tropical Storms for Annual 2013, available at: http://www.ncdc.noaa.gov/ sotc/tropical-cyclones/2013/13 (last access: May 2014), 2013.
National Oceanic and Atmospheric Administration, National Weather Service, National Hurricane Center: Storm Surge Overview, available at: http://www.nhc.noaa.gov/surge, last access: September 2014.

Nicholls, R. J., Hoozemans, F. M., and Marchand, M.: Increasing food risk and wetland losses due to global sea-level rise: regional and global analyses, Global Environ. Change, 9, S69-S87, 1999.

O'Brien, J. S.: Modeling tsunami waves and ocean storm surges with FLO-2D, in: American Water Resources Association, 2005 Summer Specialty Conference, Institutions for Sustainable Watershed Management, Honolulu, Hawaii, 2005.

Rygel, L., O'Sullivan, D., and Yarnal, B.: A method for constructing a social vulnerability index: an application to hurricane storm surges in a developed country, Mitig. Adapt. Strat. Global Change, 11, 741-764, 2006.

Wu, S.-Y., Yarnal, B., and Fisher, A.: Vulnerability of coastal communities to sea-level rise: a case study of Cape May County, New Jersey, USA, Clim. Res., 22, 255-270, 2002.

Yumul Jr., G. P., Cruz, N. A., Servando, N. T., and Dimalanta, C. B.: Extreme weather events and related disasters in the Philippines, 2004-08: a sign of what climate change will mean?, Disasters, 35, 362-382, doi:10.1111/j.1467-7717.2010.01216.x, 2011. 